\title{
SEISMIC RETROFITTING OF HIGHWAY TRUSS BRIDGES
}

\author{
Charles Seim ${ }^{1}$; Phillip Yen ${ }^{2}$ and Jerome S. O'Connor ${ }^{3, *}$ \\ ${ }^{1}$ Consulting Engineer, San Francisco, CA 94111 USA, E-mail: cjseim@pacbell.net \\ ${ }^{2}$ Research Structural Engineer, Federal Highway Administration, 6300 Georgetown Pike, McLean, \\ VA22101 USA,E-mail:wen-huei.yen@fhwa.dot.gov \\ ${ }^{3}$ Senior Program Officer, Transportation Research, MCEER, University at Buffalo, State University of New York, \\ Buffalo, New York 14261 USA \\ *(Corresponding author: E-mail: jso7@buffalo.edu)
}

Received: 22 June 2005; Revised: 8 May 2006; Accepted: 10 May 2006

\begin{abstract}
This paper presents a summary of the recently released document entitled Seismic Retrofitting Guidelines for Complex Steel Truss Highway Bridges (referred to here as the Guidelines). The Federal Highway Administration (FHWA), commissioned MCEER (formally known as the Multidisciplinary Center for Earthquake Engineering) to develop guidelines for seismic retrofitting of steel truss highway bridges as part of a larger research project. The Guidelines list various types and articulations of trusses and define bridge performance levels under the actions of a lower-level (LL) and an upper-level (UL) earthquake. The Guidelines present methods of structural analysis, from simple linear-elastic to dynamic non-linear, time-history, to determine demand on the structure. Methods are presented for determining the capacities of the truss members and there are several examples of retrofit strategies.
\end{abstract}

Keywords: bridge, truss, retrofit, retrofitting, seismic

\section{INTRODUCTION}

Seismic Retrofitting Guidelines for Complex Steel Truss Highway Bridges [1] was produced by MCEER at the University at Buffalo under the sponsorship of the FHWA. It extends the state of practice for seismically retrofitting steel truss bridges on the highway system within the United States, using research advances in seismic engineering and recent experiences from steel truss highway bridge seismic retrofitting projects.

During the last century, trusses were the bridges of choice for highway structures requiring long, high, or multi-spanned crossings. Throughout the USA, truss bridges were built in a variety of types and configurations, and in locations varying from very high to very low seismicity. Although the number of this type of structure is falling as they are replaced by more contemporary styles, there were still 14,334 truss bridges remaining as of 2004. Researchers and practitioners have learned from studying bridge performance during recent earthquakes, from analytical studies, and from laboratory testing, that truss bridges may be vulnerable to damage and collapse in an earthquake. Structural deterioration from rust can accentuate the problem.

The AASHTO Standard Specifications [1] cover seismic design and construction for ordinary highway bridges with spans less than $150 \mathrm{~m}$ and a 75-year design life. No present specifications cover the seismic retrofit of highway truss bridges with design life over 75 years; with spans longer than $150 \mathrm{~m}$; with multiple truss spans, unusual geometry, or unusual mass and stiffness distribution. The Guidelines are specifically written to include both the seismic retrofit of these complex truss bridges and the seismic retrofit of standard truss bridges.

An important new document on bridge retrofitting is the two-part Seismic Retrofitting Manual for Highway Structures. It also was developed by MCEER with the sponsorship of FHWA. It is based on a previous edition of the manual, but updated with information on recent seismic research 
and professional practice. This new document was issued in late 2006. Part 1 of this Manual is titled Seismic Retrofitting Manual for Highway Bridges, Part 1: Bridges and focuses on the seismic retrofitting of conventional highway bridges. It is intended to be applicable nation-wide in the USA for all levels of seismic hazards and for conventional concrete substructures and steel and concrete girder-type highway bridges with spans less than $150 \mathrm{~m}(500 \mathrm{ft})$ and a design life limited to 75 years. Suspension bridges, cable-stayed bridges, arches, long-span trusses, and movable bridges are not covered; however, many of the procedures and techniques presented can be applied to these types of structures, if appropriate judgment is used.

Seismic Retrofitting Truss Highway Bridges, which is the subject of this paper, specifically extends the seismic retrofit provisions of the Seismic Retrofitting Manual for Highway Structures, Part 1: Bridges to cover the seismic retrofit of both ordinary steel truss highway bridges and of seismically-complex and long-span steel truss highway bridges.

The truss Guidelines are divided into the following sections.

(1) Introduction - presenting the seismic characteristics of steel truss highway bridges.

(2) Philosophy and Procedures - covering the approaches to and the methods of seismic retrofitting of steel truss highway bridges.

(3) Screening and Prioritization - presenting methods of determining seismically deficient highway truss bridges and prioritizing the scheduling of bridges requiring retrofitting.

(4) Analysis

(5) Design Parameters

(6) Evaluation Methods - which gives methods of analysis to determine seismic demands and capacities, ranging from simple calculations to non-linear, dynamic analyses.

(7) Retrofit Measures - providing several overall retrofit strategies which consist of evaluating several retrofit approaches, and selecting specific retrofit measures to modify the structural members.

(8) Case Histories

(9) Glossary

(10) References and Bibliography

\section{SEISMIC PROVISIONS FOR BRIDGE DESIGN IN THE USA}

The major turning point of modern seismic engineering of bridges in the United States began with the 1971 earthquake in the San Fernando Valley of California. In 1973, the California Department of Transportation responded to public outcry to make highway bridges safe from earthquake collapse by issuing new seismic design criteria for bridges in California. This was the first attempt in the US to relate peak ground accelerations, as are shown on seismic hazard maps, to different soil types at bridge sites; to the dynamic-response characteristics of the structure; and to force-reduction factors that account for inelastic behavior. This FHWA-backed seismic design criteria formed the basis for the seismic provisions in the 1977 AASHTO Standard Specifications for Highway Bridges.

In 1978, the FHWA awarded a contract to the Applied Technology Council (ATC) [2] to develop improved seismic design guidelines for highway bridges that are applicable to all regions of the USA. The product of this effort was the ATC-6 Seismic Design Guidelines for Highway Bridges published in 1981. 
FHWA followed this pioneering work by publishing, in 1983, Report No. FHWA/RD-83/007, Seismic Retrofitting Guidelines for Highway Bridges. This was the first document that focused exclusively on providing nationally-applicable guidance to the bridge design profession for seismic evaluation and retrofitting of highway bridges. In 1987, FHWA published Report No. FHWA-IP-87-6, Seismic Design and Retrofit Manual for Highway Bridges, which updated and expanded the 1983 work into a manual for the design and retrofit of highway bridges.

The 1987 document was followed, in 1995, by the FHWA Publication No. FHWA-RD-94-052, Seismic Retrofitting Manual for Highway Bridges. This 1995 Manual incorporated the experience gained from use of the 1987 publication, new knowledge gained from analytical and laboratory research, and reconnaissance trips to earthquake-devastated areas to review structural damage. The 1995 Manual was developed as an interim document with the expectation that it would be revised and updated in a few years.

The FHWA 1995 Manual has now been revised, updated, and expanded by MCEER as the two-volume Seismic Retrofitting Manual for Highway Structures. Part 1, Bridges (referred to here as the Bridge Retrofitting Manual), incorporates the experience gained from recent earthquakes and the intense seismic-research effort that has recently been developed and conducted in several structural testing laboratories. Part 2 is completely new material pertaining to retaining structure, slopes, tunnels, culverts, and roadways.

Results of the National Cooperative Highway Research Project (NCHCRP) 12-49, published in 2003 as Recommended LRFD Guidelines for the Seismic Design of Highway Bridges, is another important product of current research. This document is entirely design-related and does not cover seismic retrofitting of highway bridges.

\section{SEISMIC RESEARCH AT MCEER}

MCEER, (formerly known as the Multidisciplinary Center for Earthquake Engineering) in Buffalo, NY has a fully-equipped laboratory that performs a variety of public and private research projects, has an active production of publications, and also conducts research for the U.S. Department of Transportation's Federal Highway Administration. A series of long-term contracts has been used over the years to administer a comprehensive research program that is developed through a consortium of university researchers with contributions from practitioners, all of whom are leaders in their field.

The goals for each FHWA project that has been awarded to MCEER are established primarily through an assessment of needs expressed by the bridge engineers in the American Association of State Highway and Transportation Officials (AASHTO) and overseen by an independent Highway Seismic Research Council (HSRC).

Because of the immediacy of the need to improve seismic safety of existing bridges on the national highway network, including both cities and country roads, and to update design procedures for new bridges, the MCEER contracts are primarily applied research with an emphasis on deliverables that are practicable and are immediately implementable. The contracts provide for sharing these products with the engineering profession through workshops and the products are usually published in standard specification formats and in manuals of practice.

As with previous MCEER contracts with the FHWA, the current contracts place emphasis on a particular theme. The Project 112 Contract, recently completed, deals with the design of new 
highway bridges. Project 106 Contract, which is nearing completion, deals with the existing population of highway bridges and appropriate seismic retrofitting requirements to increase their seismic capacity and to reduce the risk of collapse.

The current contract, Project 094, is a six-year program entitled Seismic Vulnerability of the Highway System, which deals with special or long span bridges. The scope includes laboratory testing of steel bridge components; developing bridge loss estimating methods; and developing standards of practice, such as methods of seismic isolating highway girder bridges or seismic retrofitting highway truss bridges, the subject of this paper.

Project 094 addresses bridge safety in six major emphasis areas:

Task B: Seismic Risk Analysis

Task C: Special Bridges

Task D: Response Modification

Task E: Geotechnical and Foundations

Task F: Special Studies such as seismic monitoring of long span bridges

Task G: Technology Transfer

The Guidelines presented here are part of the scope of work under Task C. One of the subtasks in Task $\mathrm{C}$ is to develop retrofit procedures for steel truss highway bridges that are not covered by the standard AASHTO, ASD (Allowable Stress Design), or LFD (Load Factor Design) specifications. An important part of this task is the development of a technical reference, i.e. the Guidelines, that will provide specific recommendations for assessing vulnerabilities of these existing bridges and making seismic retrofitting improvements. Since approximately $80 \%$ of existing span bridges longer than about $75 \mathrm{~m}$ are trusses, the focus of this subtask is on the truss structure type. The objective is to give agencies responsible for these structures guidance for screening, prioritizing, and retrofitting highway truss bridges. In the future, subsequent manuals will be developed that will specifically address other bridge types, such as cable supported bridges and moveable bridges.

The Guidelines have been prepared by a team of authors at T. Y. Lin, International, Inc. located in San Francisco, CA. As design engineers on several major retrofit projects, they have been able to offer a unique, practical perspective on the subject. Contributions from other consulting firms involved in other projects have also been incorporated. The document has also benefited from an extensive peer review period.

The primary reference document for the new Guidelines is the Bridge Retrofitting Manual noted above. It is currently in the final stages of review at the FHWA. This document greatly enhances earlier versions of the highway bridge retrofitting manuals of the FHWA, and gives broad guidance on screening, evaluating, and retrofitting bridges. An equally important document incorporated by reference is a summary report on Foundation Design for Special Bridges being prepared by Dr. Geoff Martin, under MCEER 094 Task C.

This is a summary of the events leading to the development of the Guidelines, the document that is the subject of this paper.

\section{GUIDELINES SECTION 1 - INTRODUCTION}

The most prolific bridge type constructed in the last 100 years or more for highway structures, in the span range of about $50-\mathrm{m}$ to $350-\mathrm{m}$, is the steel truss. Most of these 14,334 truss bridges were designed to much lower seismic requirements than seismic design specifications require today. 
The public demanded earthquake-safe bridges after experiencing the bridge failures in the 1989 Loma Prieta and the 1994 Northridge earthquakes. In the New Madrid seismic zone alone, there are 2618 trusses and of these, $69 \%$ are considered structurally deficient.

Steel truss highway bridges are generally defined as a framework of straight steel members forming triangular patterns that are connected together to form a primary load-supporting system, called a truss. The triangle is the characteristic basic unit of a truss bridge configuration because a triangle is the most inherently stable geometric figure. Generally, two primary trusses are spaced apart by floor beam members framed into the vertical posts, or into the apex of the diagonals. The floor beams support longitudinal stringers, which support the concrete deck on which vehicles travel.

Secondary members fulfill important functions, such as forming a lateral bracing system in a horizontal plane at the upper and lower chord level, and the lateral bracing system acts to carry transverse wind and seismic loads longitudinally to the truss supports. Secondary cross bracing in the vertical plane at the panel points acts to space the trusses apart to match the floor beam spacing and to fulfill the important function of stiffening the rectangular cross-section against sway distortions.

\subsection{Types of Steel Truss Bridges}

Trusses are classified by the position of the deck within the cross section of the bridge. If the deck is in the plane of the top chords, the bridge is referred to as a deck truss; when the deck is in the plane of the lower chord, the bridge is referred to as a through truss. If the deck is between the top and bottom chords, the bridge is called a half-through truss. In 2003, there were 13,563 through trusses and 770 deck trusses in the National Bridge Inventory.

\subsection{Steel Truss Articulation}

Trusses can also be classified by the articulation of the truss at its support points and at the inter-span hinged points. The articulation of a truss is determined by the type and location of its support points.

A single span, supported by bearings at each end, is called a Simple Span Truss. A Cantilever Truss refers to the construction method in which the truss in erected by balanced-cantilevering out from each of the two center towers. A suspended span is usually connected to the tips of the cantilever arms by eye bars or by hanger plates and it functions as a simple span.

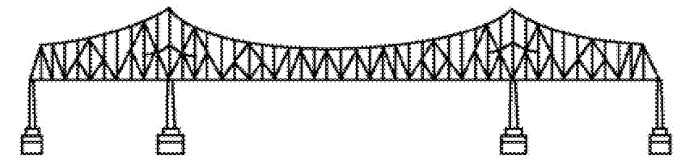

Variable Depth Cantiever

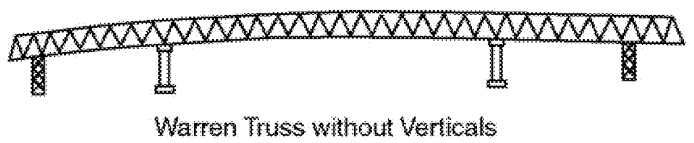

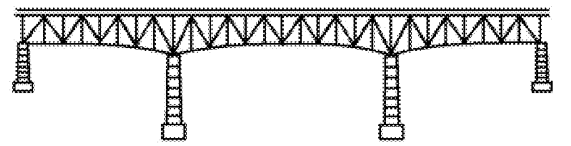

Deck Truss

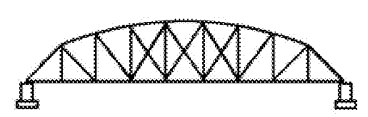

Camelback Truss

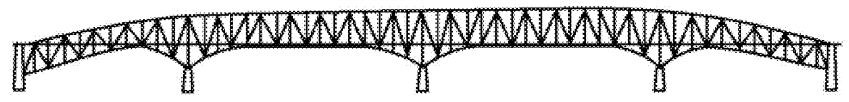

Hateff-knough Tuss

Figure 1. Examples of Continuous Truss Highway Bridges 
A Continuous Truss is, as it name implies, continuous over each of the piers that support the truss. Continuous Trusses are generally limited to four spans. The position of the deck, as denoted by the terms "through" with the deck positioned in the plane of the lower chord, or "deck" with the deck positioned in the plane of the upper chord, is usually placed after the truss classification term, i.e., Simple Span Deck Truss, or Cantilever Through Truss.

\subsection{Structural Classifications of Steel Trusses Used for Highway Bridges}

Most steel truss highway bridges can be classified into the following truss types and articulation methods:

- Steel Truss Types

○ Through Truss

- Half-through Truss

- Deck Truss

- Pony Truss

- Bow- String Trusses

- Articulation Methods

- Simple Span

- Cantilever

- Gerber

- Continuous

- Combination

\subsection{Lateral Load Resisting Systems}

Most trusses have stiff sway-frames, called portals or portal frames, at each support point of the truss. The function of the portal frames is to carry wind loads from the lateral bracing system in the plane of the upper chord down to the bridge bearings that support the truss at each support point. However, in a seismic event, the portal frames will perform the same function as they do for wind: carrying the seismic lateral forces down to the truss bearings.

Trusses are usually supported on structural steel bearings, sometimes called "shoes," that carry vertical gravity loads and lateral wind and seismic loads to the substructure. Rockers and nested rollers are usually used for bearings that are designed to move to accommodate thermal movements. Bearings that are rigidly connected to the substructure fix the truss from longitudinal movement. The bearings are the last link in the lateral load-resisting system as they connect to the substructure, which must then have its own separate force-resisting load path to the ground.

An important seismic characteristic of most highway truss bridges is that the center of mass of the superstructure is well above the support bearings. In an earthquake, the high position of the mass of the superstructure generates inertia forces that produce large overturning moments in the bearings at the support points of the truss.

\subsection{Concrete Decks}

Often the concrete decks of truss bridges have joints supported by the floor beams every three or four panel points. The function of these joints is to reduce the lateral load-carrying participation of the concrete deck through composite action with the truss chords under live load flexure. These joints also reduce the participation of the concrete deck through composite action with the truss chords in resisting wind and seismic lateral loads. The concrete decks of trusses are connected to the abutment roadway slabs or to adjacent trusses, in multi-span truss arrangements, by thermal 
joints that accommodate temperature movements.

\subsection{Seismic Classification of Truss Bridges}

\subsubsection{Seismically-Ordinary truss bridges}

In the AASHTO LRFD Standard Specifications for Highway Bridges for both Allowable Stress Design (ASD) and for Load Factor Design (LFD), the Introduction states, "[these specifications] apply to ordinary highway bridges, and supplemental specifications may be required for unusual types and for bridges with spans longer than $150 \mathrm{~m}(500 \mathrm{ft})$ ". Thus the AASHTO, ASD and LFD bridge design specifications recognize that there are both long-span and unusual types of bridges that are not covered within the AASHTO specifications for the design of ordinary bridges, and that unusual types of bridges require special supplemental specifications for their design. The Guidelines classify these special truss bridges as Seismically Complex Truss Bridges (SC Bridges).

\subsubsection{Seismically-Complex truss bridges}

Damage to bridges from recent earthquakes and seismic investigations and analyses of bridge structures have demonstrated that there are also unusual configurations of steel truss highway bridges that behave under seismic excitation in a manner that is not covered by the AASHTO standard bridge specifications. These unusual configurations of truss bridges are classified as SC Bridges. A Seismically-Complex Truss Bridge is defined as meeting one or more of the truss bridge configurations listed below.

- A truss span exceeding $150 \mathrm{~m}$.

- Deck-trusses or double-deck trusses.

- A series of truss spans creating a long bridge with multiple supports exceeding seven spans.

- A series of truss spans creating a long bridge with a total length exceeding $500 \mathrm{~m}$.

- Truss bridges that have unusual geometry or alignment, skews exceeding 20 degrees, or unusual mass or stiffness distribution.

- Movable bridges that swing, lift, or tilt open with truss superstructures.

\section{GUIDELINES SECTION 2 - SEISMIC RETROFIT PHILOSOPHY AND PROCESS}

\subsection{Retrofit Philosophy for Truss Bridges}

The basic concepts for retrofitting truss bridges, presented in the Guidelines, are based on the following concepts.

- Minimize loss of life and serious injury to the traveling public from unacceptable bridge performance.

- These provisions for high, moderate, and low seismicity should be applicable to all regions of the United States.

- Bridge designers should not be restricted from using new and innovative concepts and approaches in the seismic retrofit or seismic design of bridges.

\subsection{Performance Criteria and Performance Levels}

Owners, with the help of bridge engineers, should decide which one of four performance levels that their retrofitted truss bridge should meet. The Life Safety performance level (PL-1) is to prevent bridge collapse and loss of life, although the bridge may need extensive repairs or replacing. For 
bridges on lifeline routes, the performance level must be set to provide full service soon after a seismic event, including the maximum expected event.

Performance Levels for the seismic retrofitting of an existing bridge are given below:

Table 1. Bridge Performance Levels

\begin{tabular}{|l|l|}
\hline Performance Level & \multicolumn{1}{|c|}{ Damage } \\
\hline PL-0 & No minimum level of performance is specified. \\
\hline PL-1 & $\begin{array}{l}\text { Sustained damage is significant after a large earthquake and service is } \\
\text { significantly disrupted, but life safety is assured. The Bridge may need } \\
\text { to be replaced after a large earthquake. }\end{array}$ \\
\hline $\begin{array}{l}\text { PL-2 } \\
\text { Operational }\end{array}$ & $\begin{array}{l}\text { Sustained damage is minimal and limited service for emergency } \\
\text { vehicles is available after inspection and clearance of debris. The } \\
\text { Bridge is repairable, but with restrictions on traffic flow during repair. }\end{array}$ \\
\hline PL-3 & $\begin{array}{l}\text { Sustained damage is negligible and full service to all traffic is available } \\
\text { after inspection and clearance of debris. Damage that does occur is } \\
\text { repairable without interruption to traffic flow. Negligible damage may } \\
\text { include evidence of small movement and minor damage to } \\
\text { non-structural components, but no evidence of inelastic response in } \\
\text { structural members or permanent deformations of any kind. }\end{array}$ \\
\hline
\end{tabular}

\subsubsection{Damage definitions}

Minimal damage includes minor inelastic response and narrow flexural cracking in concrete. Permanent deformations are not apparent and repairs can be made under non-emergency conditions with the possible exception of superstructure expansion joints, which may need removal and temporary replacement or bridge over with temporary steel plates immediately after the seismic event.

Significant damage includes permanent offsets and cracking, yielded reinforcement, major spalling of concrete, which may require a bridge closure to repair. Partial or complete replacement of columns may be required. Foundations should not be damaged except in the event of large lateral flows due to liquefaction, in which case inelastic deformation in piles is permitted.

\subsection{Earthquake Levels}

The lower level (LL) earthquake is the largest earthquake that has a reasonable probability of occurrence within the lifetime of the bridge, i.e. it represents a relatively small but likely event. Accordingly, the lower level earthquake was selected with a return period of about 100 years. The upper level (UL) earthquake is an earthquake that has a finite, but remote, probability of occurrence within the life of the bridge, i.e. it represents a large and rare event and a return period of about 1000 years was selected.

\subsection{Bridge Importance}

The Guidelines define two classes of bridge importance: Essential Bridges and Standard Bridges. In the Guidelines, all essential truss bridges are classified as Seismically Complex (SC) Bridges, because, by definition, they are non-standard truss bridges. All other truss bridges are classified as Seismically Standard Truss Bridges (SS Bridges). 


\subsection{Anticipated Service Life}

An important factor in deciding the extent to which a complex bridge should be seismically retrofitted is the anticipated service life (ASL) of the structure. Seismic retrofitting of a complex bridge with a short service life may be difficult to justify in view of the very low likelihood that the design earthquake will occur during the remaining service life of the structure.

Complex truss bridges usually have anticipated service life much longer than ordinary AASHTO truss bridges of 75 years. Although these types of bridges may have been designed according to an AASHTO bridge design specification that implies a design life of 75 years, many of these types of complex truss bridges do, in fact have longer service life. This is because some of these SC Bridges are generally more costly to design and construct so that there is a large investment in the facility.

\subsection{Selection of Minimum Performance Level}

Minimum performance levels for SC Bridges are given in Table 2 according to earthquake size and service life category. All SC are classified as Essential Bridges. These are minimum recommended levels. If retrofitting to these levels cannot be justified economically, the owner may choose a lower level. The owner may also choose a higher level than that recommended here for certain classes of bridges. Examples are bridges on the National Highway Network, which are critically important to the operation of national or regional transportation routes.

Table 2. Minimum Performance Level

\begin{tabular}{|l|l|l|l|}
\hline \multirow{2}{*}{ Earthquake } & \multicolumn{3}{|c|}{ Service Life Category (Essential Bridges) } \\
\cline { 2 - 4 } & ASL 1 & ASL 2 & ASL 3 \\
\hline Lower Level & PL 1 & PL 2 & PL 3 \\
\hline Upper Level & PL 1 & PL 1 & PL 3 \\
\hline Fault Rupture & PL 1 & PL 1 & PL 1 \\
\hline
\end{tabular}

\section{GUIDELINES SECTION 3 - SCREENING AND PRIORITIZATION}

\subsection{Screening of Truss Bridges}

The first step in implementing a screening method for truss bridges is to compile a bridge inventory to obtain the following basic information:

- The structural characteristics of each bridge to determine vulnerability rating

- The soil conditions and seismicity at the bridge site to determine a seismic hazard rating

- The truss bridge performance level, its importance to the transportation system and its value to the socio-economics of the community

The bridges classified as SS Bridges from the first-screening level need to be further screened in a second- screening level that determines if any of these standard truss bridges meet the physical definition of SC Bridges.

\subsubsection{Prioritization of SC truss bridges:}

The objective of a prioritization program is to determine the order of retrofitting a population of of truss bridges that were found to be SC by the screening program. A number of factors must be considered in any prioritization program: 
- The bridge as a symbol and an economic link to the community

- Bridge importance

- Physical condition of the truss and of the substructure supporting the truss

- Serviceability of the truss. Many truss bridges were built with two narrow lanes, light truck loading, or low clearance levels

- Anticipated Service Life. A bridge in poor physical condition, or one that is already scheduled for structural or functional rehabilitation, may be given a higher priority for seismic retrofitting.

- Cost of seismic retrofit. If the cost of the seismic retrofitting approaches about 75 percent of the cost of a new bridge, bridge replacement should be considered.

\section{GUIDELINES SECTIONS 4, 5, \& 6 - ANALYSIS, DESIGN PARMETERS, AND EVALUATION METHODS}

There are several methods for the seismic analysis of truss bridges and also several different ways in which to express their capacity. These lead to a matrix of possibilities for the capacity/demand evaluation of truss bridges. The matrix of possibilities considered in the Guidelines are shown in Table 3. Examples of "subsystems" of a truss bridge are a portal frame at the end of a span, a sway frame, or a support tower.

Table 3. Approaches to Demand Analysis and Capacity Evaluation

\begin{tabular}{|l|l|c|c|c|}
\hline \multicolumn{2}{|c|}{ Demand Analysis } & \multicolumn{3}{c|}{ Capacity Evaluation } \\
\cline { 3 - 5 } \multicolumn{2}{|c|}{} & \multicolumn{2}{|c|}{ Member } & Subsystem \\
\cline { 3 - 5 } & Strength & Ductility & Displacement \\
\hline \multirow{3}{*}{ Elastic } & Modal & XX (C) & & XX (D2) \\
\cline { 2 - 5 } & $\begin{array}{l}\text { Time } \\
\text { History }\end{array}$ & X & & X \\
\hline Inelastic & $\begin{array}{l}\text { Time } \\
\text { History }\end{array}$ & X & XX (E) & XX \\
\hline
\end{tabular}

An $\mathrm{X}$ in the table indicates a feasible combination of analysis method and approach to capacity evaluation. The most sensible and/or common combinations are indicated with XX. Also indicated in parentheses in Table 3 is the general equivalence to the methods of analysis described in the Bridge Retrofitting Manual. Demands may be calculated using either elastic or inelastic analysis methods.

The capacity of members can be expressed either in terms of force - the strength of the member, or deformations - the ductility of the member. A force approach will be suitable for most problems. Only for members subjected to inelastic demands, will it be necessary to consider the ductility of the member. Members which are particularly likely to be subjected to inelastic demands are those occurring in support towers, for example.

\subsection{Methods of Analysis}

The three methods of analysis for the seismic analysis of truss bridges are, in increasing order of complexity:

- Elastic modal analysis with response spectrum input

- Elastic time history analysis with ground motion input

- Inelastic time history analysis with ground motion input 
The choice of method depends on both the level of seismic hazard, and on the complexity and importance of the structure. The dependence on seismic hazard is perhaps more clear; an inelastic analysis would only be warranted if the demands are large enough to produce inelastic response. A complex detail or an important structure might warrant a time history analysis to obtain simultaneous force demands in order to realize an efficient retrofit or a more accurate evaluation that would make it possible to avoid a retrofit altogether. Analysis may also be required to obtain the displacement capacity of portal frames, sway frames, support towers, or other subsystems of truss bridges. The displacement capacity may be obtained from a pushover analysis of a model of the subsystem.

\subsection{Modeling Techniques}

\subsubsection{Global modeling}

Seismic analysis of truss bridges may be generally accomplished using three-dimensional finite element analysis, as for other bridge structures. Although truss members primarily resist tension and compression, it is usually preferable to model them using three-dimensional beam elements with flexural properties.

\subsubsection{Properties of built-up members}

The section properties of built-up members may be computed by integration over the cross-section, using the same mechanics of materials approach as for solid sections. Laces used to connect different elements of a cross-section together usually do not contribute to the axial or the flexural stiffness of the section. The laces do contribute to the shear and torsional stiffness of a built-up member, however. Indeed, the laces are the major component of the shear and torsional stiffness of many members.

\subsubsection{Modeling of tension only members (Eyebars)}

Eyebars and similar members constructed from flat plates may be unable to resist compression forces. Typically, these members are under dead load tension, and the issue of their compression capacity - or lack thereof - only arises if the dynamic force in a member exceeds its initial tension. In this case, an elastic analysis will predict a net compression in the member, which is not physically realizable.

\subsubsection{Modeling of buckling of compression members}

It may occur that the predicted compression force in a compression member exceeds its compression capacity, which is usually limited by buckling. The behavior is likely to be inelastic - either straightforward yielding or inelastic buckling - with the formation of a plastic hinge near the middle of the member. Possibly, a small overstress may be considered acceptable, if the member in question is compact and able to withstand inelastic straining without too much degradation of response. In cases of significant overstress, or if a member is not compact, it's probably better to model its inelastic response.

\subsubsection{Inelastic response of built-up members}

The ability of the cross-section to sustain inelastic strains depends on its compactness - on the compactness of its individual components in the case of a built-up member. Testing of large-scale models is a reliable method of proving the capability of a member. However, useful results can also be obtained by inelastic finite element analysis, if this is performed by experienced engineer. 
Such an analysis may need to include such refinements as: geometric nonlinearity, inelastic material, initial imperfections, and residual stresses, in order to obtain meaningful results.

\section{GUIDELINES SECTION 7 - RETROFIT MEASURES}

\subsection{Definition of Terms}

When a bridge is evaluated and found to be seismically deficient, the next step is to decide what retrofit strategy, if any, should be used to correct the deficiencies. Decision-making may be formalized by exploring different retrofit strategies and comparing the cost estimates and other implications of each. A Retrofit Strategy is the overall plan for the seismic retrofit of a bridge. This plan can employ more than one retrofit approach and thus several different retrofit measures. Retrofit Approach is a method of improving or correcting the seismic deficiencies of the bridge. Strengthening and isolation are examples of a retrofit approach. Retrofit Measure is the physical modification of a component in a bridge for the purpose of improving or correcting seismic deficiencies of the bridge.

\subsection{The Do-nothing, Retrofit, and Replacement Options}

The three retrofit performance levels should be weighed against the 'do-nothing' option, incurring loss of service after an event, and with the higher costs of a full-service replacement option. The decision to do nothing will be relatively straightforward if life-safety is the only performance requirement, and if the expected damage, such as total span-collapse, is not a threat to life-safety and the loss of bridge.

\subsection{Members}

The two general approaches are the addition of stiffeners to decrease the slenderness of any longitudinal plates, and the addition of cover plates to increase the strength.

\subsubsection{Stiffener retrofit}

If the plates that make up a member are slender, the strength of the member may be limited by local buckling of those plates. The addition of appropriately designed stiffeners will reduce the width-to-thickness ratio of the plates to which they are applied. An example of stiffening a member to improve is ductility is shown in Figure 2-1: 


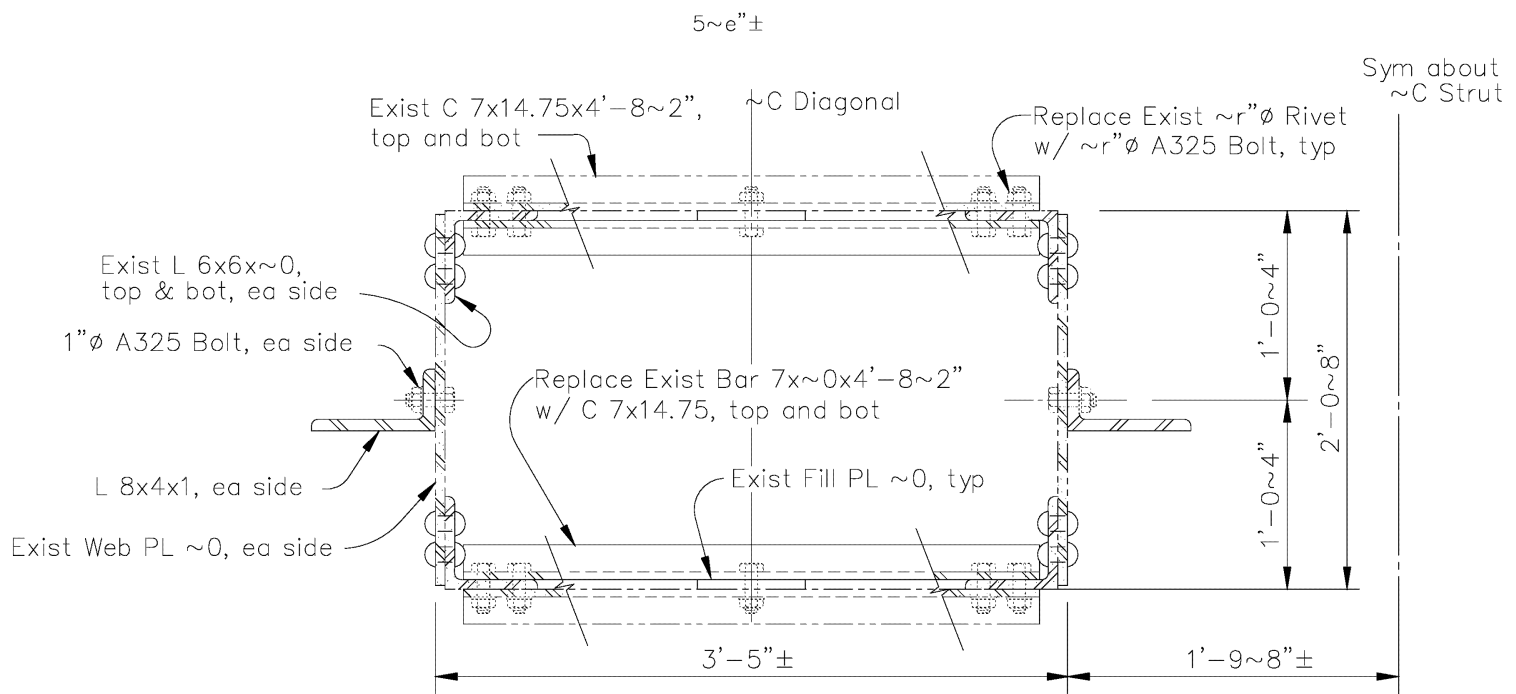

Figure 2-1. Plate Retrofit with Stiffeners

\subsubsection{Cover plate retrofit}

Cover plates may be added to strengthen a member in both tension and compression. An example is shown in Figure 2-2:

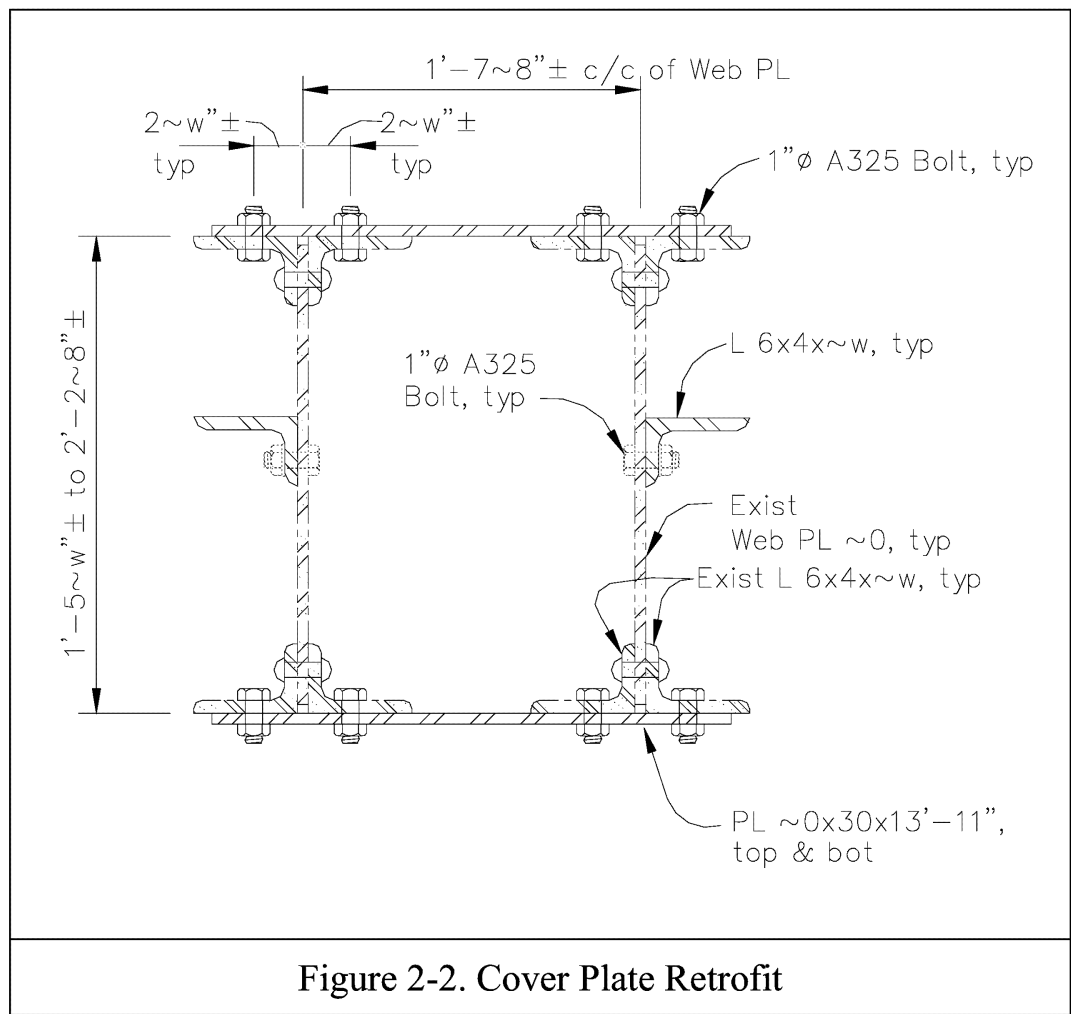




\subsubsection{Connections}

Truss bridges constructed before the Second World War used riveted connections between the truss members and the gusset plates. After the war, rivets continued to be used, but high strength bolts were developed which could be tightened with an easy-to-use pneumatic wrench, so bolts gradually replaced rivets.

\subsubsection{Existing connections and splices}

Existing connections and splices, between or within members having a ductility demand-to-capacity ratio greater than unity shall be strengthened, if necessary, so that their nominal capacity is at least $25 \%$ greater than the nominal capacity of the members they connect. Riveted connections may be readily strengthened by replacing the rivets with high strength bolts.

\subsection{Cost Considerations}

Cost is a major consideration in seismic retrofitting. The average construction cost of seismic retrofitting is much higher than the incremental cost of adding seismic resistance at the time of new construction. Engineering costs for retrofit evaluation and design are also higher than the engineering costs for new construction. It is realistic to expect that the costs of seismically retrofitting a truss bridge may be two or three times the cost required for providing seismic resistance in a new bridge of similar value. Since seismically complex bridges are unique, they often require customized retrofit strategies. The standardization of retrofit details is, therefore, difficult to achieve. In addition, detailed seismic evaluation of a bridge and the identification of the most appropriate retrofit strategy is a time-consuming process, which may involve detailed dynamic analysis and many trials in the investigation of possible strategies.

The life of seismic retrofitting need not exceed the remaining service life of the bridge. The annualized seismic retrofitting cost of an existing bridge is increased because of the shorter life of the retrofit compared to the annualized cost of adding seismic resistance to a new bridge with a longer service life. These facts should be considered during the selection of the most appropriate retrofit strategy for ordinary and seismically complex bridges

\section{CASE STUDIES, GLOSSARY, REFERNCES, AND BIBLIOGRAPHY}

In support of the concepts presented in the Guidelines, there are brief summaries of actual retrofit projects. Relatively few have been accomplished and those that have been done have been on a site specific basis. These Guidelines are a first attempt at consolidating information that might be useful to a designer for future projects. While the costs provided may not be applicable on future rehabilitations, they give an indication of the magnitude of effort involved with such projects.

Further information is provided in the numerous references cited and in the bibliography provided.

\section{SUMMARY}

This paper presents a synopsis of the role of the FHWA and the MCEER in seismic research and in the development and the publication of research papers and standards of practice, such as these truss Guidelines. The Guidelines list the various types of trusses, defines distinct performance levels and levels of earthquakes with short and long return periods. It presents methods of 
structural analysis from simple linear-elastic to dynamic, non-linear, time-history, and it presents design criteria to determine the capacity of truss members for determining demand-capacity ratios. The Guidelines include examples of retrofit measures. The document is available for purchase at http://mceer.buffalo.edu as is the new Seismic Retrofitting Manual for Highway Structures.

\section{ACKNOWLEDGEMENTS \& DISCLAIMER}

The Guidelines were produced by MCEER's research team under FHWA Contract DTFH61-98-C-00094. The contents are the sole responsibility of the authors and do not constitute official policy. It is presented to researchers and practitioners for interest only. The authors gratefully acknowledge the work of T. Y. Lin International Inc., and especially Dr. Tom Ho, P.E. who assembled a team of practicing engineers to author the Guidelines.

\section{REFERENCES}

[1] American Association of State Highway and Transportation Officials, "Standard Specifications for Highway Bridges", $17^{\text {th }}$ Ed., 2002.

[2] Applied Technology Council, "Improved Seismic Design Criteria for California Bridges: Provisional Recommendations", Report ATC-32, Redwood City, CA, 1996. 